\title{
ANALISIS PERANAN COST CONTROLLER DALAM PENGENDALIAN BIAYA OPERASIONAL DAN PENDAPATAN OPERASIONAL PADA HOTEL MERCURE MANADO TATELI BEACH RESORT
}

\author{
Esterlin Uhise $^{1}$, Hendrik Manossoh ${ }^{2}$, I Gede Suwetja ${ }^{3}$ \\ 1,2,3, Jurusan Akuntansi, Fakultas Ekonomi dan Bisnis, Universitas Sam Ratulangi, Jl. Kampus Bahu, Manado, \\ 95115, Indonesia \\ E-mail : esterlinuhise@yahoo.com
}

\begin{abstract}
The purpose of this study is to determine whether the role of cost controller in operational costs and operating income goes well or not at Mercure Manado Tateli Beach Resort hotel. The data used to analyze the role of cost controller that is qualitative data, while based on the source using primary and secondary data. The method used in this research descriptive method, which aims to provide a clear picture of the object of research. The results showed that the role of cost controller in the control of operational costs and operating income at Mercure Manado Tateli Beach Resort hotel is running well and in accordance with the SOP
\end{abstract}

Keywords: Cost controller, Operational Cost, Operating Income

\section{PENDAHULUAN}

Industri perhotelan adalah salah satu industri yang berperan penting dalam perkembangan ekonomi dan dunia pariwisata Indonesia. Secara umum hotel di definisikan sebagai bangunan perusahaan atau usaha yang menyediakan jasa penginapan, makanan, minuman bagi tamu dan juga di sertai dengan fasilitas lainnya. Hotel adalah jasa penjualan penginapan yang merupakan suatu kegiatan yang dilakukan oleh perusahaan dalam usahanya memasarkan produk atau jasa yang dimiliki kepada masyarakat atau konsumen yang membutuhkan. Hasil pendapatan penjualan di sebut dengan pendapatan biaya opersional merupakan sumber pendapatan bagi perusahaan yang akan mendukung kegiatan perusahaan selanjutnya. Aktivitas penjualan merupakan aktivitas yang terpenting diantara berbagai macam aktivitas yang ada dalam perusahaan, karenanya aktivitas penjualan memerlukan penanganan yang serius. Dengan demikian penjualan merupakan faktor yang sangat penting untuk diawasi melalui pengendalian manajemen yang memadai agar mencapai hasil pengembalian yang optimal atas investasi. Semakin berkembangnya perusahaan, manajemen mempunyai keterbatasan dalam mengawasi secara langsung kegiatan perusahaan. Oleh karena itu, dibutuhkan informasi yang cepat, tepat dan akurat sebagai alat bantunya. Informasinya yang baik dapat dihasilkan apabila perusahaan menerapkan suatu sistem akuntansi yang dapat menggambarkan proses pelaksanaan kegiatan operasional secara jelas dan terstruktur, sesuai dengan tujuan perusahaan.

Oleh karena itu perusahaan memerlukan seorang controller yang dapat merencanakan, mendesain, mengawasi, mengkoordinasikan dan menyediakan laporan serta memberikan saran yang dapat membantu pimpinan perusahaan dalam mengambil keputusan. Controller harus memahami keadaan perusahaan, memiliki pengetahuan yang cukup dalam bidang akuntansi dan memiliki pandangan yang luas. Dalam pengendalian penjualan, controller dapat memberikan analisis serta mempunyai pengaruh penting dalam pemecahan dan pengambilan keputusan yang bijaksana sejalan dengan tujuan jangka panjang perusahaan 
Agar controller berperan dengan baik, pihak manajemen penjualan harus terbuka dengan saran-saran dan menanggapi setiap alternatif pemecahan yang diberikan oleh controller Dengan adanya pengendalian penjualan yang dilakukan oleh controller diperusahaan, maka kemungkinan penyimpangan-penyimpangan yang terjadi dapat dikurangi seminimal mungkin dan diharapkan eektivitas penjualan dapat tercapai. Dapat di simpulkan bahwa di tengah persaingan yang cukup ketat dan inflasi yang berpengaruh secara langsung maupun tidak langsung biaya perusahaan kemudian biaya tersebut berpengaruh terhadap harga jual maupun laba perusahaan, industri perhotelan di hadapkan dengan tantangan untuk dapat memaksimalkan laba sekaligus menentukan harga jual yang kompetitif, namun tanpa menurunkan kualitas pelayanan agar tetap sesuai standar.

Karena itu diperlukan pengendalian internal terhadap biaya masuk dan keluar. Pengendalian internal di perlukan dalam perusahaan agar kegiatan operasional perusahaan efektif dan efesien sehingga tujuan perusahaan tercapai yakni memperoleh laba yang optimal, oleh karena itu ada bagian khusus di dalam hotel yang menangani hal tersebut yakni cost controll. Cost control bertugas untuk melakukan analisis terhadap biaya yang dikeluarkan (aktual) dengan jumlah yang telah direncanakan oleh manajemen sebelumnya (anggaran).

\section{TINJAUAN PUSTAKA}

2.1 Cost controller

Cost controller dalam bahasa Indonesia adalah pengendali biaya, ada banyak sebutan dipergunakan untuk jabatan kepala akuntansi; akan tetapi sebutan yang paling umun dan representatif adalah controller. Tugas-tugas controller kadang-kadang dipikul oleh seorang kepala akuntansi, manajer kantor, controller, bendaharawan, asisten bendaharawan, atau sekretaris.

\subsubsection{Prinsip-Prinsip Controller Berlaku Terhadap Semua Jenis Perusahaan}

Salah satu rintangan terhadap perkembangan fungsi controller adalah perasaan pada sebagian pimpinan, bahwa perusahaannya berbeda dan tidak memerlukan metode pendalian yang modern. Fungsi controllership tidak terbatas pada perusahaan-perusahaan besar saja. Sebuah perusahaan tidak perlu terlebih dahulu menjadi perusahaan besar untuk dapat memberikan kesempatan yang luas bagi seorang controller yang cakap untuk membuktikan kegunaan dan nilainya bagi perusahaan.

\subsubsection{Fungsi-Fungsi Dasar Controller}

Perencanaan (planning) menetapkan dan memelihata suatu rencana operasi yang terintegrasi sejalan dengan sasaran dan tujuan perusahaan, baik jangka pendek maupun jangka panjang, menganalisa, merevisi, mengkomunikasikan kepada semua tingkat manajemen serta menggunakan sistem-sistem dan prosedur-prosedur yang cocok. Pengendalian (control) mengembangkan dan merevisi norma yang memuaskan sebagai ukuran pelaksanaan dan menyediakan pedoman serta bantuan kepada para anggota manajemen yang lain dalam menjamin adanya penyesuaian hasil pelaksanaan yang sebenarnya terhadap norma standar.

Pelaporan (reporting) menyusun, menganalisa dan mengintepretasikan hasil-hasil keuangan untuk digunakan oleh manajemen dalam proses pengambilan keputusan, mengevaluasi data dalam hubungannya dengan tujuan perusahaan dan tujuan satuan orgnisasinya. Akuntansi (accounting) mendisain, menetapkan dan memelihara sistem akuntansi keuangan dan biaya pada semua jenjang perusahaan, termasuk untuk perusahaan secara menyeluruh, per divisi, per pabrik dan per satuan, utnuk dapat mencatat secara wajar semua transaksi keuangan dalam pembukuan agar sesuai dengan prinsip-prinsip akuntansi yang sehat, disertai dengan pengendalian intern yang memadai. 


\subsubsection{Kualifikasi Controller}

Kualifikasi controller yang efektif adalah sebagai berikut: Dasar teknis yang sangat baik dalam akuntansi dan akuntansi biaya, disertai suatu pengertian dan pengetahuan yang menyeluruh mengenai prinsip-prinsip akuntansi. Pemahaman terhadap prinsip-prinsip perencanaan, pengorganisasian dan pengendalian. Pemahaman umum mengenai jenis industri dalam mana perusahaan tergolong dan pemahaman terhadap kekuatan social, ekonomi dan politik yang terlibat.

Pemahaman yang mendalam mengenai perusahaan, termasuk teknologi, produk, kebijaksanaan, tujuan sejarah organisasi dan lingkungannya. Kemampuan untuk berkomunikasi dengan semua tingkat manajemen dan suatu pemahaman dasar terhadap masalah fungsional lainnya yang berhubungan dengan teknik, produksi, pembelian, hubungan masyarakat dan pemasaran. Kemampuan untuk menyatakan ide dengan jelas, secara tertulis ataupun dalam penyajian yang informative. Kemampuan menggerakkan orang-orang lain untuk mencapai tindakan dan hasil yang positif.

\subsection{Pengertian Biaya}

Pendapat biaya oleh Siregar (2014:23) yaitu cost adalah pengorbanan sumber ekonomi untuk memperoleh barang dan jasa yang diharapkan memberikan manfaat sekarang atau masa yang akan datang.

Menjalankan suatu usaha membutuhkan biaya yang harus dikeluarkan agar perusahaan mampu terus berkualitas. Biaya sendiri merupakan hal yang sangat penting dan tidak terpisahkan dalam menentukan harga pokok produksi. Dengan biaya, perusahaan juga dapat menentukan laba yang diperoleh perusahaan.

Dari defenisi diatas dapat disimpulkan bahwa biaya dapat diartikan sebagai nilai pengorbanan untuk memperoleh barang dan jasa yang berguna untuk masa yang akan datang atau mempunyai manfaat melebihi satu periode akuntansi yang diukur dalam satuan uang.

\subsection{Biaya Operasional}

Pemikiran oleh Carter dan Usry (2004:29) mendefenisikan "Biaya (Cost) sebagai nilai tukar, pengeluaran, pengorbanan untuk memperoleh manfaat, sehingga dalam akuntansi keuangan, pengeluaran atau pengorbanan pada saat akuisisi diwakili oleh penyusutan saat ini atau dimasa yang akan datang dalam bentuk kas atau aktiva lain".Pendapat Machfoedz (2000:36) mendefenisikan "Biaya adalah jumlah yang diukur dalam bentuk keuangan dari kas yang dikeluarkan atau kekayaan yang dipindahkan, saham yang dikeluarkan atau hutang yang dibentuk dalam hubungannya dengan barang atau jasa yang diperoleh ". Pendapat Mowen dan Handsen (2000:36) mendefenisikan "Biaya adalah nilai ekuivalen kas yang dikorbankan untuk mendapatkan barang atau jasa yang diharapkan memberi manfaat saat ini atau dimasa yang akan datang bagi organisasi atau perusahaan ".Tiada konsepsi anggaran yang dapat memenuhi berbagai macam tujuan, oleh karena itu terdapat bermacam-macam penggolongan biaya operasional.

\subsubsection{Jenis Jenis Biaya Operasional}

Beban atau biaya operasional untuk perusahaan memproduksi barang jadi pada umumnya terdiri dari :

Pendanaan umum

Dana yang di kelompokkan ke dalam biaya administrasi umum ada 4 ( empat ) yaitu sebagai berikut :

Kegiatan yang berkaitan dengan hasil kerja karyawan yang meliputi diantaranya uang bulanan karyawan, insentif dan bonus, premi lembur, pajak pendapatan, upah honoran dan lain-lain. Kesejahteraan karyawan yang meliputi pengobatan karyawan, rekreasi dan olahraga, pendidikan dan lain-lain. Biaya reparasi dan pemeliharaan yang meliputi reparasi dan pemeliharaan untuk peralatan-peralatan kantor, alat transportasi, gedung dan lain-lain. 
Beban penyusutan aktiva tetap yang meliputi biaya pencetakan, alat tulis dan perlengkapan kantor, biaya listrik dan air, biaya telphone dan lain-lain.

Biaya Pemasaran

Edy (2000:15) menyatakan biaya pemasaran adalah biaya yang meliputi semua biaya dalam rangka kegiatan pemasaran atau kegiatan untuk menjual barang dan jasa perusahaan kepada pembeli sampai dengan pengumpulan piutang menjadi kas. Sedangkan pendapat Kotler dan Keller (2016) menyatahkan pemasaran adalah Marketing is about identifying and meeting human and social needs. One of the shortest good definitions of marketing is meeting needs profitably. Anggaran finance adalah semua biaya dalam rangka fungsi finansial yaitu fungsi penentuan dana yang ada di perusahaan. Dengan demikian, biaya pemasaran digolongkan menjadi sebagai berikut :

Anggaran administrasi dan advertensi, seperti pembuatan papan iklan, brosur dan iklan lewat media masa. Anggaran untuk melayani pesanan, biaya yang terjadi dalam rangka memenuhi atau melayani pesanan yang di terima dari pembeli yang terdiri dari : Beban penggudangan dan penyimpanan produk jadi yang meliputi : beban bagian gudang, reparasi dan pemeliharaan, penyusutan gudang dan peralatannya, asuransi gudang dan lain-lain.

Pengeluaran pengepakan dan pengiriman yang meliputi : gaji pengepakan dan pengiriman, biaya perlengkapan pengepakan dan biaya angkut barang.

Anggaran penagihan kredit dan penagihan piutang.

Anggaran administrasi penjualan yang meliputi : gaji bagian administrasi penjualan, perlengkapan kantor dan lain-lain.

\subsection{Pendapatan Operasional}

Pengahasilan operasional adalah terdiri atas semua pendapatan yang merupakan hasil langsung dari kegiatan usaha bank yang benar benar telah diterima. Financial Accounting Standards Board (FASB) menyatakan bahwa penghasilan merupakan arus masuk atau kenaikan pada nilai harga satuan usaha atau penghentian hutang-hutang atau kombinasi dari keduanya dalam satu periode yang didapatkan dari pemberian/produksi barang-barang, pemberian jasa dan pelaksanaan aktivitas ekonomi lainnya, tidak semua perusahaan sama dalam mengartikan suatu pendapatan dikarenakan perusahaan dibawah ini melakukan aktivitas usaha yang berbeda-beda diantaranya, Kongsi jasa memperoleh pendapatan dari hasil memberikan pelayanan jasa kepada konsumen dan memperoleh imbalan dari pelayanan yang diberikan.

\subsection{Penelitian terdahulu}

Beberapa penelitian terdahulu yang penulis jadikan sebagai bahan pertimbangan dalam melakukan penelitian pada Hotel Mercure Manado Tateli Beach Resort. Penelitian yang dilakukan oleh Wardi Jeni tahun 2012 tentang Peran controller dalam perencanaan dan pengendalian pada hotel Grand Elite Pekanbaru, menyatakan bahwa secara umum Grand Elite Pekanbaru telah menerapkan peranan controller. Adapun penelitian oleh Nugraha Putra tahun 2008 tentang peranan controller dalam pengendalian biaya promosi untuk meningkatkan volume penjualan(studi kasus pada hotel bumi karsa bidakara jakarta) menyatakan bahwa hasil penelitian sebagai bahan pertimbangan dan masukan bagi management hotel bumi karsa bidakara jakarta penulis menyarankan agar controller meningkatkan perannya dalam melakukan analisa penyimpangan setiap bulannya hal ini bertujuan untuk fungsi pengendalian yang lebih baik,Sedangkan Togas Olviani tahun 2016 tentang analisis peranan cost controller dalam penngendalian biaya rota hotel menyatakan Peranan cost controller pada PT Rota internasional hotel sudah sesuai dengan SOP yang ada meski tidak berperan terhadap penurunan biaya secara langsung 


\section{METODE PENELITIAN}

\subsection{Jenis Penelitian}

Jenis penelitian yang digunakan dalam penelitian ini adalah jenis penelitian kualitatif dan jenis data kuantitatif. Bila ditinjau dari tujuan dan sifatnya penelitian ini bersifat deskriptif dan cenderung menggunakan analisis. Penelitian ini bertujuan untuk mengetahui peran cost controller dalam pengendalian biaya operasional dan pendapatan operasional. Didalamnya terdapat upaya mendiskripsikan, mencatat dan menganalisis kondisi yang terjadi saat ini. Pendapat Arikunto (2013:3), mendefinisikan penelitian deskriptif adalah penelitian yang dimaksudkan untuk menyelidiki keadaan, kondisi atau hal lain-lain yang hasilnya dipaparkan dalam bentuk laporan penelitian.

\subsection{Waktu dan Tempat Penelitian}

Penelitian dilakukan pada hotel Mercure Manado Tateli Beach Resort di Jl Raya Tanawangko Desa Tateli, Mandolang, Kota Manado Provinsi Sulawesi Utara. Penelitian ini dilaksanakan selama bulan Maret- April 2018.

\subsection{Prosedur Penelitian}

Mengidentifikasikan masalah, menentukan objek penelitian, penyusunan proposal penelitian, pengumpulan data, menganalisis dan mengolah data, kemudian memperoleh hasil penelitian, lalu ditarik kesimpulan dan memberikan saran.

\subsection{Metode Analisis}

Metode penelitian deskriptif kualitatif adalah sebuah metode yang digunakan peneliti untuk menemukan pengetahuan atau teori terhadap penelitian pada satu waktu tertentu (Mukthar 2013).

\section{HASIL ANALISIS DAN PEMBAHASAN \\ 4.1 Hasil analisis}

\subsubsection{Sejarah Mercure Manado Tateli Beach Resort}

Mercure Manado Tateli Beach Resort adalah hotel yang di kelola oleh jaringan hotel internasional yaitu accorhotels group. Mercure Manado Tateli Beach Resort di ambil ahli oleh managemen. Accor dari managemen Sedona Hotel Internasional pada bulan September 2013. Hotel Sedona Manado sendiri diresmikan pada bulan oktober tahun 2016 dengan kategori bintang 4 dan berlokasi di Jalan raya Tanawangko, Desa Tateli Kecamatan. Mandolang Kabupaten Minahasa Provinsi Utara.

Hotel Mercure Manado Tateli Beach Resort di miliki oleh PT. Pantai Indah Tateli, sebuah perusahaan yang bergerak di bidang usaha jasa perhotelan. Hotel Mercure Manado adalah hotel resort sehingga prospek penjualan kamar lebih diarahkan kepada tamu Internasional maupun lokal yang bertujuan untuk berlibur ataupun beristirahat. Dengan fasilitas yang lengkap baik untuk berkreasi, beristirahat dan juga untuk kegiatan bisnis maupun meeting menjadikan Hotel Mercure Manado Tateli Beach Resort adalah salah satu hotel berbintang dengan standart Internasional yang dimiliki oleh Sulawesi utara.

\subsubsection{Tugas Tiap Depertemen Hotel Mercure Manado Tateli Beach Resort}

1. Room devision

Room devision department yaitu devisi utama yang terdapat disebuah hotel yang bertanggung jawab atas seluruh operasional dari hotel terutama di bidang kamar (room). Room devision membawahi Front office dan housekeeping.

(tata usaha) yaitu departemen yang bertanggung jawab atas kebersihan hotel baik itu kamar hotel, maupun area umum hotel.

Front office department (kantor depan) yaitu departemen yang bertugas dan bertanggung jawab atas pemesanan dan penjualan kamar hotel, serta menangani tamu yang chek in maupun chek out.

2. Food and beverage department 
Food and beverange department yaitu department yang membawahi food and beverage product and beverage service.

Food and beverage product yaitu salah satu department di hotel yang bertanggung jawab atas pengelolaan bahan mentah menjadi makanan yang siap hidang, atau departemen yang bertugas untuk membuat makanan dan minuman dikicthen hotel.

3. Accounting department

Akuntansi departemen yaitu suatu department hotel yang bertanggung jawab atas masalah administrasi hotel. Akuntansi depertemen terbagi atas beberapa bagian yaitu : General cashier berfungsi mengadministrasikan penerimaan dan pengeluaran kas, income auditor berfungsi melaporkan pendapatan hotel dan bertanggung jawab atas pengendaliannya, credit berfungsi melakukan analisa kredit-kredit dan kebutuhan modal kerja hotel.

4. Engineering department

Salah satu departemen pendukung hotel yaitu suatu departemen hotel yang bertanggung jawab untuk menangani perawatan maupun perbaikan atas semua alatalat serta mesin yang ada di hotel apabila mengalami kerusakan. Purchasing department

Pembeliaan departemenyaitu suatu bagian yang bertanggung jawab atas keseluruhan pembelian pengadaan serta semua kebutuhan hotel. Tempat keamanan departemen dalah suatu bagian yang bertugas menjaga keamanan hotel maupun tamu selama menginap 24 jam.

5. Sales and Marketing department

Sales dan pemasaran departemen yaitu department atau bagian yang ada di hotel, yang bertugas atas penjualan dan pemasaran dari hotel serta bertanggung jawab untuk mengawasi seluruh kegiatan yang berhubungan dengan kegitan penjualan dan pemasaran hotel.

\subsection{Pembahasan}

\subsubsection{Peran controller yang dijalankan pada hotel Mercure Manado Tateli Beach}

1. Kemampuan dasar teknis.

Cost controller pada hotel Mercure Manado Tateli Beach Resort berpendidikan S1 dan mempunyai latar belakang pendidikan akuntansi.

2. Pemahaman terhadap prinsip-prinsip perencanaan.

Cost controller pada hotel Mercure Manado Tateli Beach Resort mempunyai pemahaman mengenai prinsip-prinsip perencanaan pengorganisasian, dan pengendalian biaya.

3. Pemahaman umum mengenai industry.

Cost controller pada hotel Mercure Manado Tateli Beach Resort mengetahui dan mengerti jenis industri mana perusahaan, yang tergolong, yatu perusahaan yang bergerak di perhotelan dan memberikan pelayanan yang baik bagi tamu tamu yang berkunjung.

4. Pemahaman mendalam mengenai perusahaan

Cost controller pada hotel Mercure Manado Tateli Beach Resort memiliki pemahaman yang mendalam mengenai profil perusahaan, termasuk sejarah perusahaan, fasilitas yang ada di hotel dan lain lain. Cost controller juga aktif dalam mengikuti seminar tentang pariwisata, dan perkembangan perusahaan.

5. Kemampuan untuk berkomunikasi

Cost controller pada hotel Mercure Manado Tateli Beach Resort memiliki kemampuan yang baik dalam bahasa nasional dan internasional, mampu berbicara dengan baik kepada wisatawan, karyawan dan masyarakat.

6. Kemampuan untuk menyatakan ide 
Cost controller pada hotel Mercure Manado Tateli Beach Resort adalah salah satu kepercayaan perusahaan. Mampu menganalisa situasi dalam hotel, dan memberikan ide-ide yang inovatif dan kreatif secara lisan maupun tulisan dengan baik.

7. Kemampuan untuk menggerakan pihak lain

Cost controller pada hotel Mercure Manado Tateli Beach Resort adalah seorang yang konsistensi dan memiliki saran-saran yang tidak dapat di ganggu gugat, dan di pengaruhi dalam mempertahankan pendapat dan pemikirannya.

\subsubsection{Analisis Peranan Cost Controller Dalam Pengendalian Biaya Operasional Dan Pendapatan Operasional}

Pengendalian biaya hotel Mercure Manado Tateli Beach pada dasarnya di lakukan oleh cost controller dan financial controller. Dalam penelitian ini di fokuskan kepada cost controller untuk peranan conroller dalam pengendalian biaya operasional dan pendapatan operasional. Berdasarkan data yang di dapat dalam penelitian tentang peranan cost controller dalam pengendalian biaya operasional dan pendapatan operasional dalam hotel Mercure Manado Tateli Beach Resort.

Data tersebut diolah untuk membahas tujuan dari penelitian yaitu untuk mengetahui apakah peranan cost controller berjalan dengan baik atau tidak dalam pengendalian biaya operasional dan pendapatan operasional pada hotel Mercure Manado Tateli Beach Resort. Maka dapat disimpulkan Peranan cost controller berjalan dengan baik karena cost controller menjalankan tugas, fungsi serta kualifikasi sesuai dengan standar operasional prosedur dan mencapai standar profit perusahaan yang telah di tentukan oleh PT. Pantai Indah Tateli. Di lihat dari tahun 2016 sampai dengan 2017 Profit perusahaan semakin meningkat.

Total dari pendapatan operasional sebesar 9,485,582,831 pada tahun 2016 dan di tahun 2017 sebesar 9,800,819,053. Di bandingkan dengan pengeluaran biaya operasional sebesar 1,699,722,484 dan 2,051,303,366 di tahun 2016 sedangkan di tahun 2017 sebesar $1,721,294,472$ dan $2,378,071,875$. Selisih dari pendapatan operasional dan biaya operasional pada tahun 2016 sebesar 5,724,556,531 sedangkan selisih biaya operasional dan pendapatan operasional pada tahun 2017 sebesar 5,701,452,706 bisa dikatakan ini cukup efesien. Menurut Sedarmayanti (2014:22) efisiensi adalah ukuran tingkat penggunaan sumber daya dalam suatu proses, semakin hemat atau semakin sedikit penggunaan sumber daya, maka prosesnya di katakan semakin efesien.

Namun dilihat dari sisi lain cost controller bisa melakukan upaya dengan standart control controller dengan cara mengawasi lebih mendalam agar biaya operasional yang di keluarkan lebih sedikit, misalnya biaya operasional house laundry, menurut pengamatan dan hasil wawancara yang di lakukan peneliti pada hotel Mercure Manado Tateli Beach Resort, house laundry adalah sebuah ruangan pada basement hotel yang isinya seluruh pakaian karyawan yang sudah di cuci dan siap pakai. Cost controller bisa memberikan ide ide, serta saran kepada General manajer untuk membuat house laundry itu hanya menjadi tempat penggantian pakaian, namun pakaian tersebut di bawah pulang dan di cuci oleh masingmasing karyawan, dan jika takut pakaian hilang atau tidak di kembalikan oleh karyawan, cost controller bisa membuat absen pakaian dengan begitu profit perusahaan akan lebih meningkat. Karena sesungguhnya tujuan dari setiap perusahaan adalah profit tertinggi, karena dengan profit yang tinggi perusahaan bisa berkembang.

\section{KESIMPULAN DAN SARAN}

\subsection{Kesimpulan}

Berdasarkan penelitian yang dilakukan pada hotel Mercure Manado Tateli Beach Resort dapat dikemukakan beberapa hal yang dapat di simpulkan sebagai berikut: 
a) Peranan cost controller pada hotel Mercure Manado Tateli Beach Resort dikatakan berjalan dengan baik hal ini diketahui dari karakteristik yang mendukung perannya sebagai controller yang baik, yakni mempunyai kemampuan teknis, memahami jenis industri mana perusahaan tergolong, pemahaman mendalam mengenai perusahaan, mampu berkomunikasi dengan bahasa nasional maupun internasional, dan mampu menyatakan ide.

b) Cost controller Mercure Manado Tateli Beach Resort juga telah melaksanakan fungsi normatif dalam perencanaan, pengendalian, pelaporan, akuntansi, tanggung tanggung jawab lainnya. Hal ini dikarenakan peranan cost controller dengan sesuai dengan standar operasional prosedur (SOP).

\subsection{Saran}

Berdasarkan hasil penelitian yang dilakukan pada hotel Mercure Manado Tateli Beach Resort, saran peneliti yang bisa di sampaikan kepada hotel Mercure Manado Tateli Beach Resort. Peranan cost controller lebih di tingkatkan dalam pengendalian biaya operasional dan sebaiknya mengawasi terhadap biaya operasional agar lebih bisa meminimalisikan biaya pengeluaran hotel dengan mengikuti standart control dan memakai kualifikasi controller yaitu dapat memberikan ide-ide yang membuat perusahaan lebih maju dan lebih meningkatkan profit perusahaan

\section{DAFTAR PUSTAKA}

Arikunto, S. 2013. Prosedur Penelitian: Suatu Pendekatan Praktik. Jakarta: Rineke Cipta.

Edy, Soekarno. 2002. Sistem Pengendalian Manajemen, Edisi Revisi, penerbit PT.Gramedia pustaka utama, Jakarta.

Mukthar. 2013. Metode deskriftif kualitatif. Jakarta :GP Press Group.

Nugraha, Putra 2008. Peranan Controller Dalam Pengendalian Biaya Promosi Untuk Meningkatkan Volume Penjualan (Studi Kasus Pada Hotel Bumi Karsa Bidakara Jakarta).Skripsi. Universitas Kristen Maranatha

Kotler, Philip. Dan Kevin, K.Keller. 2016. Marketing Management, $15^{\text {th }}$ Edisi Personal Edukasi. Inc

Siregal, Baldric. 2014. Akuntansi Biaya. Edisi 2. Jakarta. Salemba Empat.

Sedarmayanti. 2014. Sumber Daya Manusia Dan Produktivitas kerja. Jakarta Mandar Maju. Togas, Olviani. 2016. Analisis Peranan Cost Controller Dalam Pengendalian Biaya Rota Hotel. Jurnal Bisnis Dan Komunikasi Kalbis Socio.

Wardi, Jeni. 2012 Peran Controller Dalam Perencanaan Dan Pengendalian Pada Hotel Grand Elite Pekanbaru.Skripsi. Universitas Lancang Kuning. 